\title{
THE DEPENDENCE OF THE FOURIER SPECTRUM OF OSCILLATIONS OF THE AMPLITUDE FUNCTION OF THE INCOMMENSURATE SUPERSTRUCTURE ON THE MAGNITUDE OF THE ANISOTROPIC INTERACTION INTERACTING WITH DZIALOSZYNSKI INVARIANT
}

\author{
S. Sveleba ${ }^{1}$ (D), I. Katerynchuk ${ }^{1}$ (D), I. Kuno ${ }^{1}$ (D), I. Karpa ${ }^{1}$, O. Semotyuk ${ }^{2}$ \\ ${ }^{1}$ Ivan Franko National University of Lviv, 107, Gen. Tarnavsky St., Lviv, Ukraine, \\ ${ }^{2}$ Ukrainian Academy of Printing, 19, Pid Holoskom St., Lviv Ukraine, \\ e-mail: incomlviv@gmail.com \\ (Received 14 September 2020; in final form 30 November 2020; accepted 02 December 2020; \\ published online 24 December 2020)
}

\begin{abstract}
The Fourier spectra of the incommensurate modulation and the dependence of the wave vector $(q)$ of the incommensurate (IC) superstructure on the magnitude of the anisotropic interaction described by the Dzialoszynski invariant $(K)$ and the long-range interaction $(T)$ are investigated. Fourier spectra in different modulation modes of incommensurate superstructure analyzed.

The calculation of the spatial changes of the amplitude and phase of the order parameter was performed by the numerical BDF (Backward Differentiation Formula) method and was performed in the Python environment using the SciPy, JiTCODE libraries according to the method described in the paper.

The parameters $T$ and $K$, which are responsible for the long-range and anisotropic interactions, respectively, in the first approximation well describe the behavior of the wave vector of the IC modulation, and its modes. The emergence of IC modulation is accompanied by the appearance of an unstable chaotic state in the case of a nonzero value of the anisotropic interaction. The increase in the value of the anisotropic interaction in the IC phase is accompanied by a change in both the frequency of existing oscillations and the magnitude of their contribution to the formation of a wave of the incommensurate modulation, causing a change in the IC modulation regime. The transition from the one mode to another is continuous. The modes themselves are determined by the domination of the contribution of the respective oscillation frequencies. The whole spectrum of possible frequencies arises at the modulation wave origin. With an increase of the anisotropic interaction, their harmonics emerge and their contribution is redistributed.
\end{abstract}

Key words: incommensurate modulation, superstructure, Fourier spectra, wave vector.

DOI: https://doi.org/10.30970/jps.24.4603

\section{INTRODUCTION}

The incommensurate superstructure arose as a result of anharmonic oscillations of structural units of crystals $\left[\mathrm{N}\left(\mathrm{CH}_{3}\right)_{4}\right]_{2} \mathrm{MeCl}_{4}(\mathrm{Me}=\mathrm{Zn} ; \mathrm{Cu} ; \mathrm{Co} ; \mathrm{Mn})$. In the course of its evolution, IC superstructure undergoes a number of modes: sinusoidal, soliton, stochastic. The sinusoidal modulation resulting from the phase transition due to the long-range interaction does not undergo pinning on the main structure or defects, which causes the absence of hysteresis effects. But in a number of works [1], it was noted that in the presence of defects and impurities in the crystal, hysteresis effects were still observed, even in the vicinity of the phase transition from the initial to the incommensurate phases. Thus, the question arises that in the sinusoidal mode of the IC modulation it can be characterized by harmonics that do not yet lead to its transition to the soliton mode. The existence of IC modulation harmonics is indicated in particular by the mechanism of the IC modulation formation from the spatial regions of the correlated motion of tetrahedral groups. Thus, in crystals $\left[\mathrm{N}\left(\mathrm{CH}_{3}\right)_{4}\right]_{2} \mathrm{MeCl}_{4}$ at the initial phase in a significant temperature range $(\Delta T \sim 30 \div 50 \mathrm{~K})$ from the phase transition to the
IC phase, the emergence of regions of correlated motion of tetrahedral groups is observed, which begin to interact with each other when approaching the phase transition temperature. The process of the formation of IC modulation is accompanied by their interaction, as shown in [2], and as a result of increasing longrange interaction (parameter $T$ ), the formation of IC modulation is accompanied by a transition through an underdeveloped chaotic state, which describes the formation of chaotic oscillations ("wandering frequencies"). Such clamped chaos (due to the insufficient range of changes in the parameters of chaos development [2]) is possible and is the germ of the existing harmonics of oscillations of the modulation of the IC in the incommensurate phase in its soliton mode. To identify such processes and the nature of the spectrum of oscillations of the IC modulation, Fourier studies of the spectra of IC modulation and the dependence of the wave vector ( $q$ ) of the IC superstructure on $T$ and $K$ parameters were performed.

The superstructures described by the free energy functional for the two-component order parameter were chosen as the objects of research. In these systems, the appearance of a incommensurate superstructure 
is due to the presence of the Livshits invariant in thermodynamic potential. The amplitude and phase of the order parameter in polar coordinates for these systems are described by two second-order differential equations [3]

$$
\begin{aligned}
R^{\prime \prime}-R^{3} & +\left(1-\varphi^{2}+T \varphi^{\prime}\right) R \\
& -R^{n-1} K(\cos n \varphi+1)=0, \\
\varphi^{\prime \prime}+2 \frac{R^{\prime}}{R}\left(\varphi^{\prime}-\frac{T}{2}\right)+R^{n-2} K \sin n \varphi & =0 .
\end{aligned}
$$

where $T=\sigma /(\gamma r)^{\frac{1}{2}}, K=2^{-\frac{n}{2}} r^{\frac{n}{2}-2} n \omega u^{1-\frac{n}{2}}$ are dimensionless parameters, $u$ characterizes the magnitude of isotropic interactions, $\omega$ is the isotropic interaction coefficient, $n$ is an integer that characterizes the symmetry of the potential, and $\eta=\left(\frac{r}{2 u}\right)^{1 / 2} R, z=\left(\frac{\gamma}{r}\right)^{1 / 2} \xi$ are dimensionless variables; $\gamma$ and $r$ are the coefficients of decomposition of thermodynamic potential; $R$ and $\varphi$ are the amplitude and the phase of the order parameter, respectively.

System (1)-(2), consisting of two second-order differential equations, was solved by the numerical BDF method.

The calculation of the spatial changes in the amplitude and phase of the order parameter was performed in the Python environment using the SciPy and JiTCODE libraries using the method described in [4].

According to expressions (1) and (2), as noted in [5], parameter $T$ describes a long-range interaction and parameter $K$ is anisotropic, which is determined by the Dzialoszynski invariant.

\section{RESULTS AND DISCUSSION}

At the beginning, we consider the dependence of the wave vector $(q)$ of the superstructure on $T$ and $K$ parameters. The obtained dependences are shown in Fig. 1; for $n=4$ (Fig. 1, a) in this case the spontaneous polarization is the phase transition parameter, and for $n=3$ (Fig. 1, b) the phase transition parameter is the spontaneous deformation. It follows from the obtained dependences that with an increase in the long-range interaction (parameter $T$ ), the magnitude of the wave vector of the IC of the superstructure increases, and with an increase in the value of the anisotropic interaction (parameter $K$ ), it decreases. The obtained phase diagram is characterized by three intervals of behavior $q$. In the spatial region $(T=0 \div 0.2, K=0 \div 1$ and $T=1.2 \div$ 1.4, $K=0 \div 4$ for $n=4$, and $T=0 \div 0.1, K=1.4$ and $T=1.2 \div 1.4, K=1 \div 1.4$ for $n=3$ ), the phase diagram (Fig. 1), the chaotic nature of the behavior of $q$ is traced. The region, where $q$ is linearly dependent on $T$ and $K$, is $T=0.2 \div 0.8, K=0 \div 2$ for $n=4$, and $T=$ $0.4 \div 0.8, K=0 \div 0.6$ for $n=3$. The region, where $q$ varies nonlinearly from the parameters $T$ and $K$, is $T=$ $1 \div 1.4, K=2 \div 4$ for $n=4$, and $T=0.80 .81 .2, K=$ $0.8 \div 1.2$ for $n=3$. Thus, the evolution of IC modulation undergoes a sinusoidal regime (where $q$ is a linear function of $T$ and $K$ ), a soliton regime (where $q$ is described by a nonlinear function of $T$ and $K$ ), and a stochastic regime (where $q$ assumes chaotic values inherent in the existence of a chaotic phase). As noted, in the process of the formation of IC modulation, a chaotic state can occur, which is "underdeveloped".

At small values of parameters $T$ and $K$, which describe the stability of the incommensurate superstructure and anisotropic interaction, respectively, this system of differential equations (1)-(2) describes the process of appearance of the incommensurate superstructure from the spatial regions of correlated motion of tetrahedral groups.

Due to the existence of uncontrolled defects and impurities in the crystal, the spatial regions of the correlated motion of tetrahedral groups are characterized by somewhat different modulation parameters.The resulting stresses at the junction of such spatial regions, in the formation of the incommensurate superstructure, lead to the appearance of harmonics of the wave of the incommensurate superstructure at small values of parameters $T$ and $K(T, K<0.001)$ [2]. The change in the phase and amplitude of the order parameter under the influence of external factors and surface energies does not cause a transition of the system to the stochastic mode with the emergence of a chaotic phase.

According to [2], the portraits of attractors of a perturbed system at small values of parameters $T$ and $K$ are characterized by a single attractor. The reason, apparently, is the small scale of the pools of attraction. In our opinion, as for the systems described in [6], this phenomenon is strongly linked to crises, in which the attractor undergoes changes in parameters caused by a collision with the boundary of the basin with changing parameters $T$ and $K$. As a result, the chaotic attractor does not arise from the cascade of doubling of the period.

It is known that with a decrease in temperature in the IC phase, the magnitude of the anisotropic interaction increases, which is especially evident in soliton and stochastic regimes. In our case, the change in parameter $K$, which describes the anisotropic interaction determined by the Dzialoszynski invariant, can be considered the equivalent of the temperature change. That is, a decrease in temperature is accompanied by an increase in the value of the anisotropic interaction. Figure 2 shows the behavior of $q$ as a function of $K$ (the dependence of $q$ on temperature) at a constant value of $T(T=1.0)$. As the value of parameter $K$ increases, the value of $q$ decreases. This dependence, as in Fig. 1, is characterized by the presence of three intervals. The first is from $T_{i}$ to $T_{1}(K=0 \div 2$, for $n=4 ; K=0 \div 0.6$ for $n=3)$, where the dependence of $q$ on $K$ is linear. At $T_{1}$, an anomalous change in the behavior of the wave modulation of the IC modulation is observed, and the transition to the second interval takes place $(K=2 \div 3.8$, for $n=4 ; K=0.7 \div$ 1.2 for $n=3$ ). In a given interval $K$, the rate of change $q$ from $K$ increases, and this dependence becomes nonlinear. This dependence also shows a number of similar anomalous stepwise changes of $q$ on $K$. 


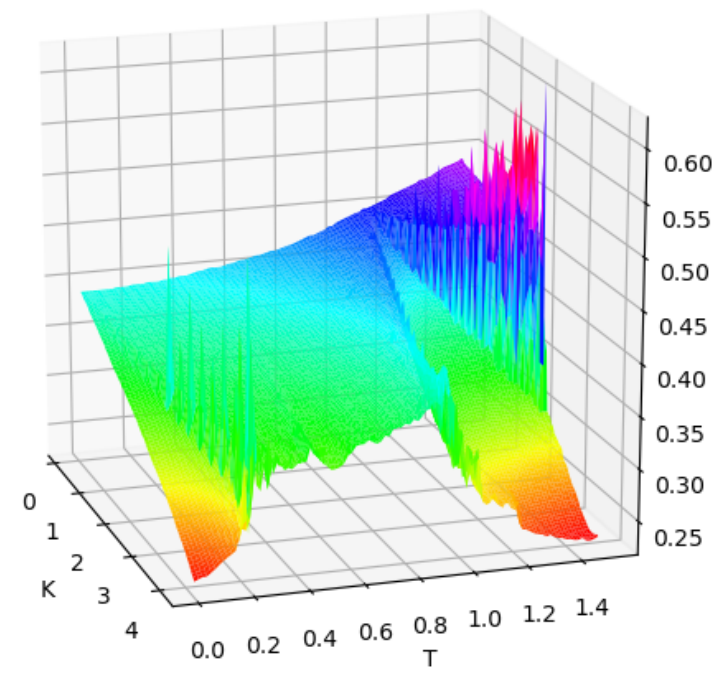

a) $n=4$

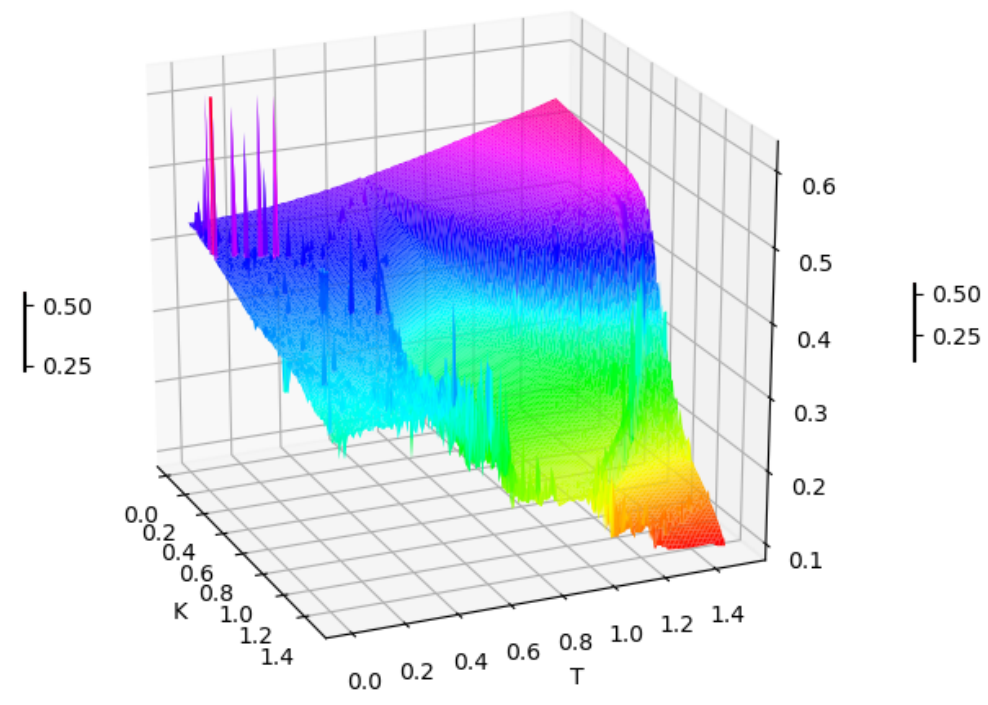

b) $n=3$

Fig. 1. (Color online.) Dependence of the wave vector $(q)$ of the incommensurate modulation on the magnitude of the long-range interaction $T$ and the anisotropic interaction $K$, which is described by the Dzialoshinski invariant

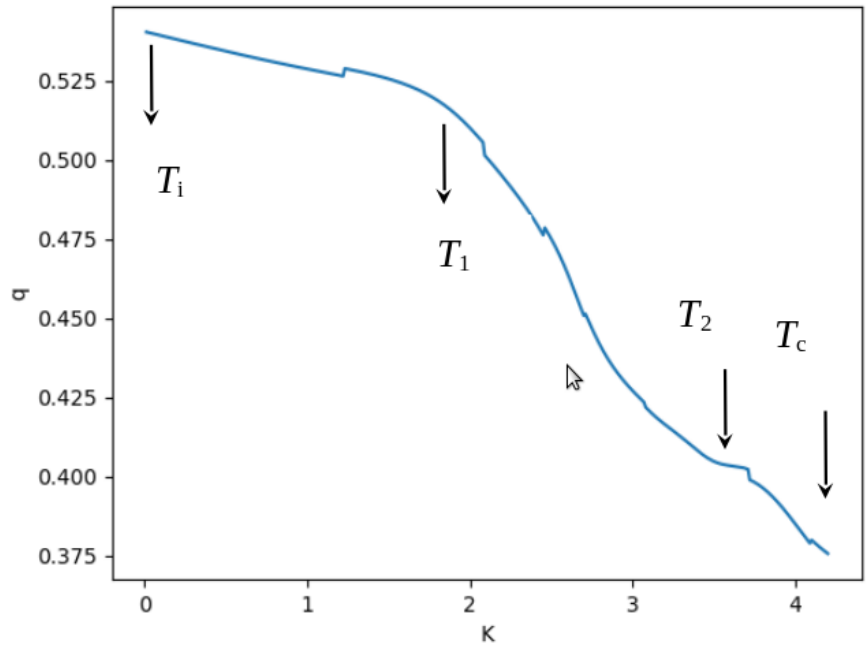

a)

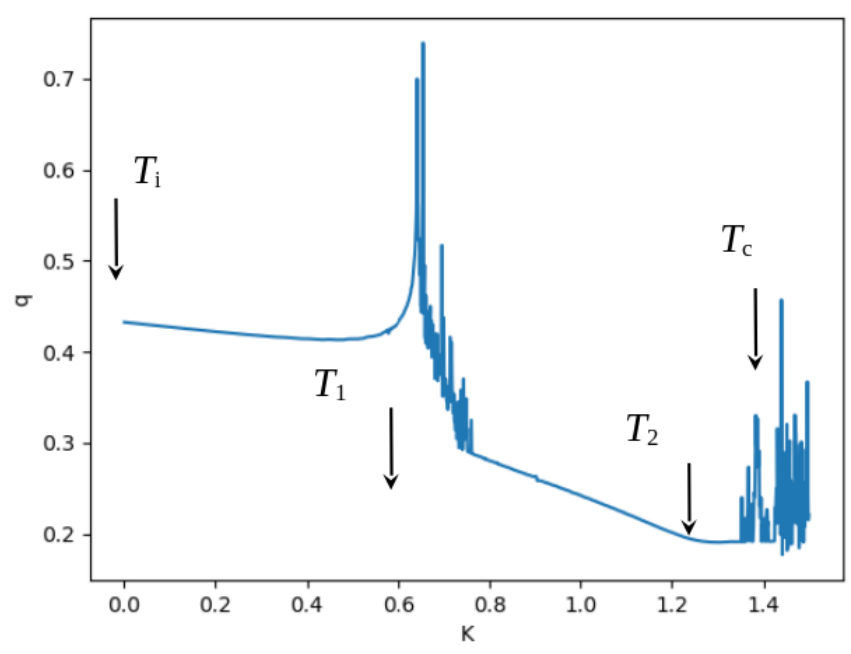

b)

Fig. 2. Evolution of the wave vector of a the incommensurate superstructure from the value of the anisotropic interaction $K$ at a constant value of $T=1.0$, provided $n=4$ a) and $n=3 \mathrm{~b}$ ), where $T_{i}$ is the temperature of transition to the incommensurate phase; $T_{1}$ - transition to the soliton mode of the superstructure; $T_{2}-$ transition to the stochastic mode of the superstructure; $T_{s}$ - phase transition to the commensurate phase

The transition to the third section is accompanied by a slowing down of the change $q \sim f(K)$, and a transition to a chaotic behavior $\left(T_{2} \div T_{c}, K>3.8\right.$ for $n=$ $4 ; K>1.2$ for $n=3)$. The obtained dependence $q \sim f$ $(K)$ is similar to the behavior of $q \sim f(T)$ for crystals of the family $\left[\mathrm{N}\left(\mathrm{CH}_{3}\right)_{4}\right]_{2} \mathrm{MeCl}_{4}$ [7]. As for the behavior of $q \sim f(K)$ for $n=4$ and $n=3$, they are similar in the first approximation. The difference between these dependences is observed only in the transition from the sinusoidal to the soliton mode $\left(T_{1}\right)$. This difference may be due to the transition from one incommensurate phase to another. As noted in [8], there is only one HC phase $(I)$ in the crystal $\left[\mathrm{N}\left(\mathrm{CH}_{3}\right)_{4}\right]_{2} \mathrm{CuCl}_{4}(n=3)$, but its structure is different $\left(I_{1}\right.$ and $\left.I_{2}\right)$ in different regions of the phase diagram.

For the small values of the magnitude of the long-range interaction $(T<0.6)$, there is the incommensurate phase $I_{1}$, and for $T \geq 1.0-$ the incommensurate phase $I_{2}$. This is the same incommensurate phase, although the behavior of the amplitude and the phase functions in them are different [9]. At $T=0.6 \div 1.0$, their coexistence is observed, which is manifested in the absence of the anomalous changes $q$ during the transition from the sinusoidal mode of IC modulation to the soliton mode. 


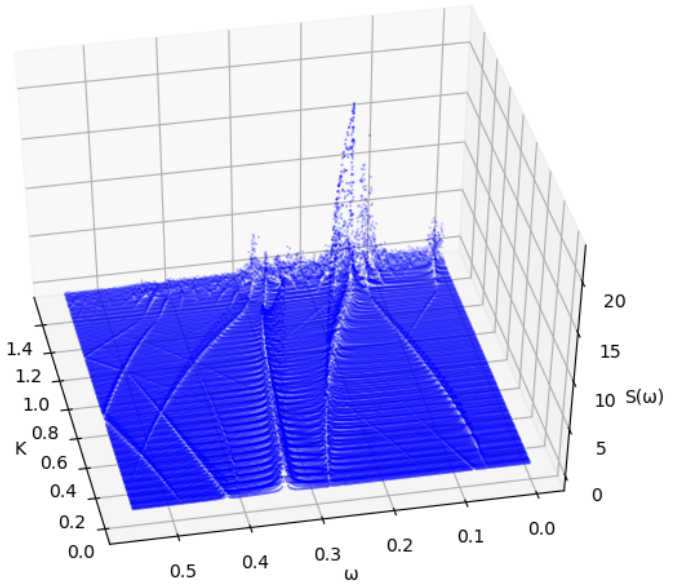

a) $n=3$

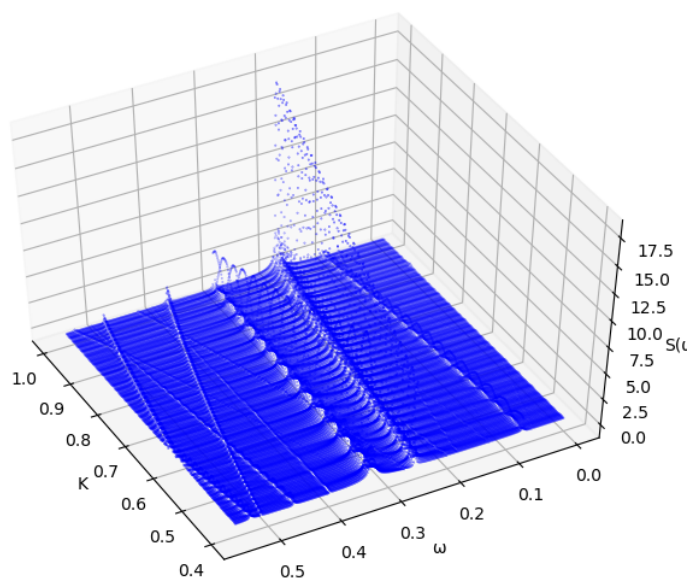

b) $n=3$

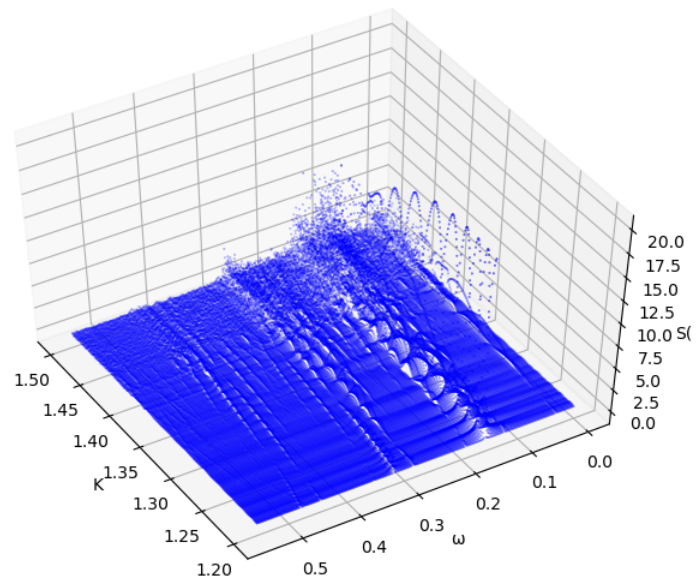

c) $n=3$

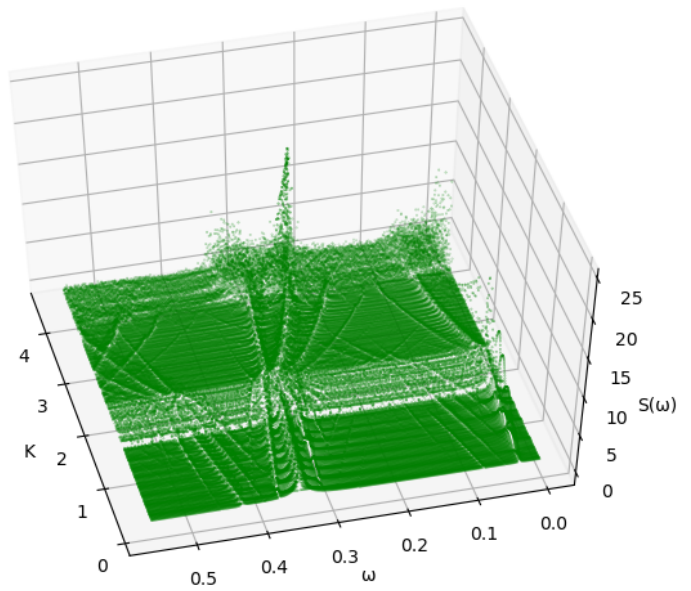

a) $n=4$

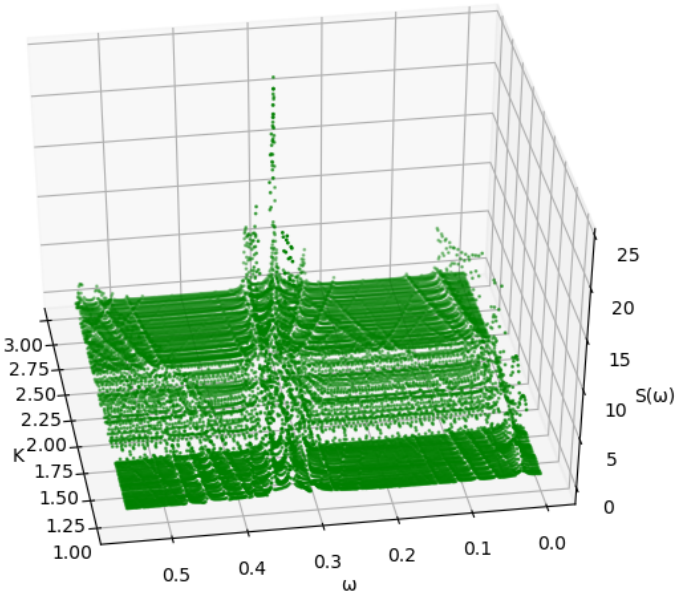

b) $n=4$

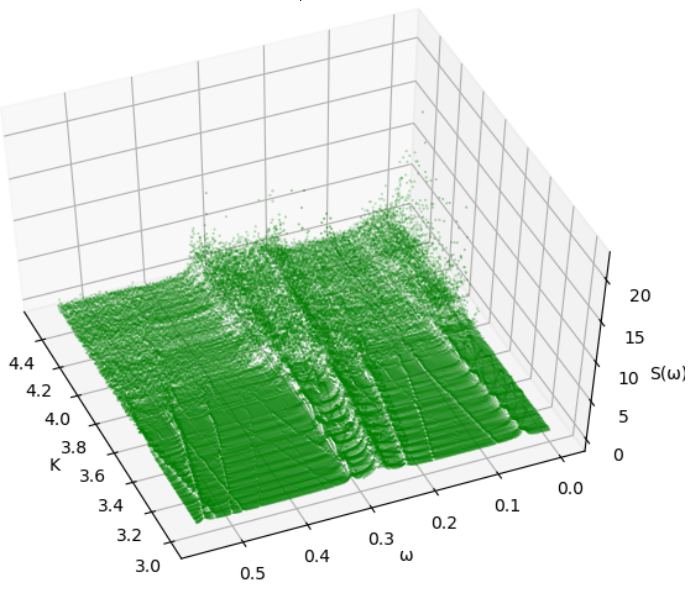

c) $n=4$

Fig. 3. The Fourier spectrum of oscillations of the amplitude function of the superstructure from the anisotropic interaction value (which is described by the parameter $K$ ) for $n=3$ and $n=4$

For a deeper understanding of the processes taking place in the IC phase, we consider the Fourier spectra of the IC phase amplitude function. In particular, we will be interested in the nature of the Fourier spectra in different modes of IC modulation. Figure 3 shows the Fourier oscillation spectra for $n=3$. The ferroelastic crystals with $n$ $=3$ include crystals $\left[\mathrm{N}\left(\mathrm{CH}_{3}\right)_{4}\right]_{2} \mathrm{CuCl}_{4}$. The spontaneous deformation arising in them serves as a parameter of the order and describes the temperature behavior of optical birefringence in the IC phase $[1,7]$. The resulting Fourier spectrum is characterized by the existence of a series of oscillations, whose frequencies change as the magnitude of the anisotropic interaction changes. Namely, as the magnitude of the anisotropic interaction $(K)$ increases, the frequency increases. 


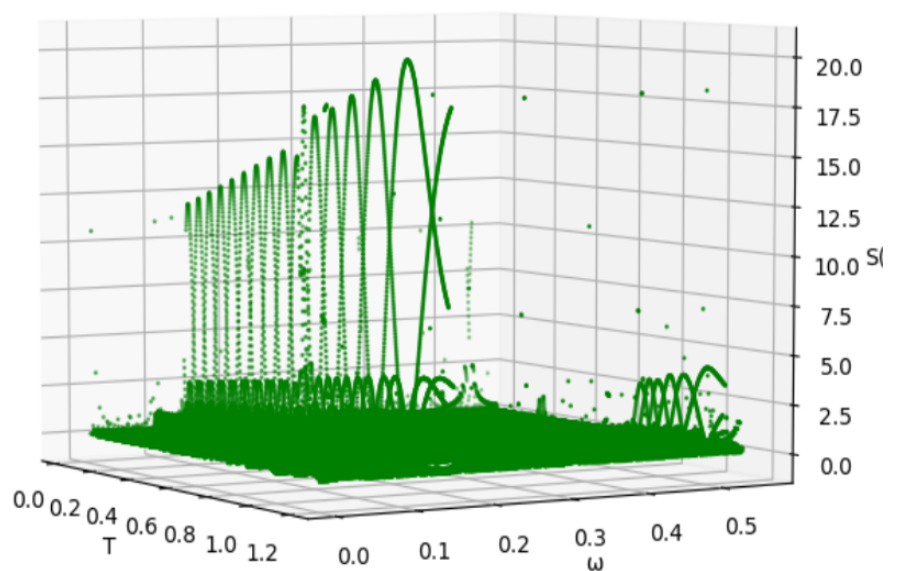

a) $K=0.01$

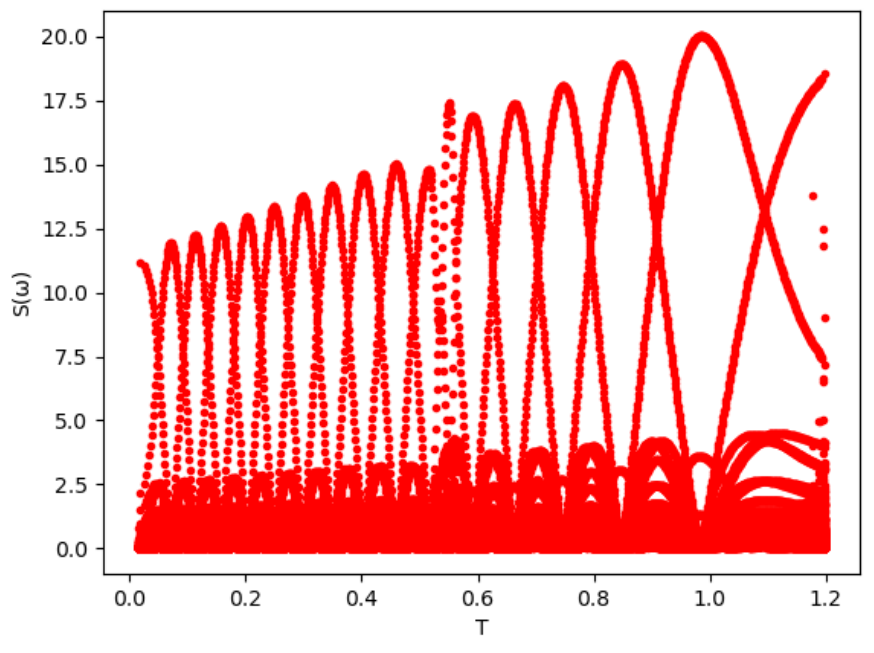

b) $K=0.01$

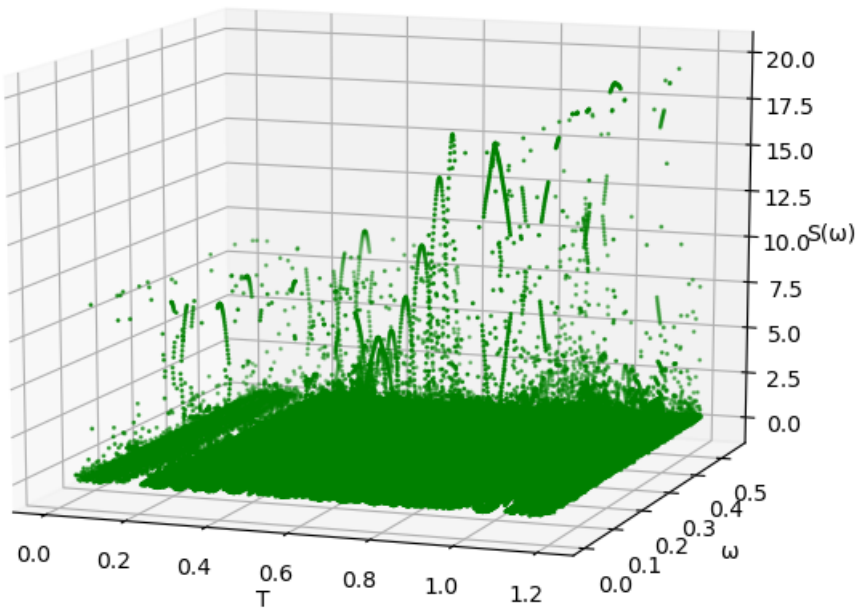

a) $K=0.3$

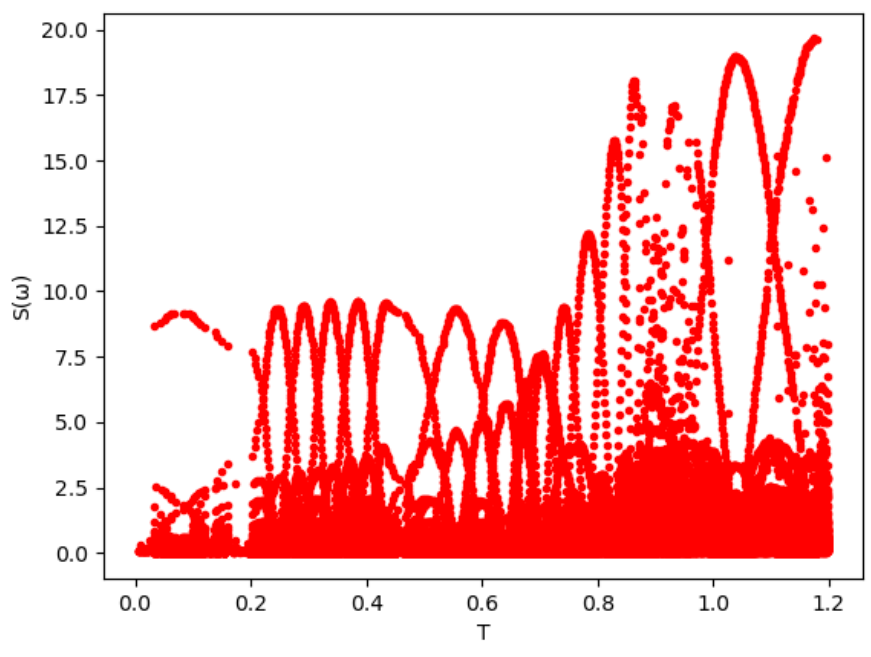

b) $K=0.3$

Fig. 4. The Fourier spectrum of oscillations of the amplitude function of the superstructure from the value of the long-range interaction (described by the parameter $T$ ) for $n=3$, at constant values of the anisotropic interaction $K$

Considering the change in the magnitude of the signal power $S(\omega)$ from $K$ (Fig. 3, b) in the vicinity of the values of $K=0.6$, one can trace the redistribution of the contribution of oscillation frequencies, and the increase in the contribution of oscillations with a smaller period. In Fig. 2, b showing the dependence of $q \sim f(K)$, in this range of values of $K$ one can trace anomalous changes in the value of $q$. Therefore, it can be assumed that the transition from the sinusoidal mode of IC modulation to the soliton mode is associated with an increase in the contribution of oscillations with a shorter period.

According to Fig. 3, the transition to chaos is accompanied by an increase in the number of existing oscillations and their harmonics. An increase in the number of oscillation frequencies is observed during the transition to the stochastic mode of IC modulation (Fig. 3, c). In the soliton mode, the redistribution of the contribution of oscillations and the appearance of new harmonics is observed.

In the process of formation of the IC modulation wave, the values of parameters $T$ and $K$ play an important role. Figures 4 and 5 show the change in $S(\omega)$ from parameter
$T$. At small values of the anisotropic interaction $(K=$ 0.01 ), the presence of harmonic oscillations (Figs. 4 and 5 ) is observed. The Fourier spectra of oscillations of the superstructure in case $K>0.1$ are characterized by the appearance of a chaotic state (Fig. $4, \mathrm{~b}$ ) at small values of parameter $T(T=0 \div 0.2$ for $n=3$, and $T=0 \div 0.1$ for $n=4)$. Therefore, in the presence of an anisotropic interaction, the formation of the modulation wave is accompanied by the appearance of an unstable chaotic state. The obtained results correlate well with the results about the influence of radiation defects and impurities, such as substitutions, on the processes of the formation of the IC modulation wave [1]. A similar pattern is observed for $n=4$ (Fig. 5 ).

To explain the obtained results, we use the experimental results to study the behavior of optical birefringence [10] and dielectric constant [11] in the vicinity of the initial- incommensurate phase transition. It is known from experimental studies that in the initial paraphase in the vicinity of the initial - incommensurate phase transition $\left(T_{i}\right)$ there are spatial regions of the correlated motion of tetrahedral groups, which determine 
the nonlinear behavior of physical quantities [7]. During the phase transition of the second type $\left(T_{i}\right)$, there is a process of merging of these regions throughout the crystal, which is accompanied by redistribution of spatial oscillations of tetrahedral groups (their rotations) in each spatial region of the correlated motion of tetrahedral groups, and the emergence of the spatial wave modulation of the incommensurate superstructure. According to

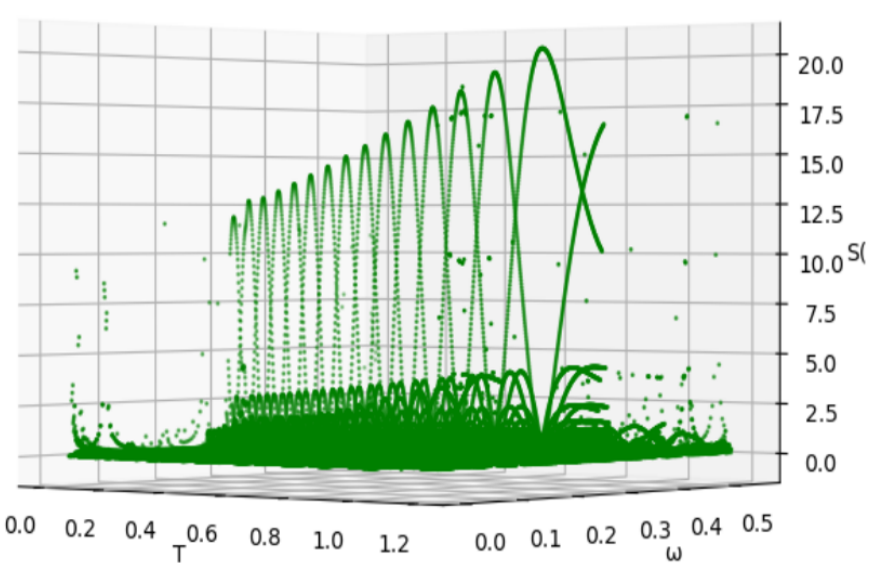

a) $K=0.001$

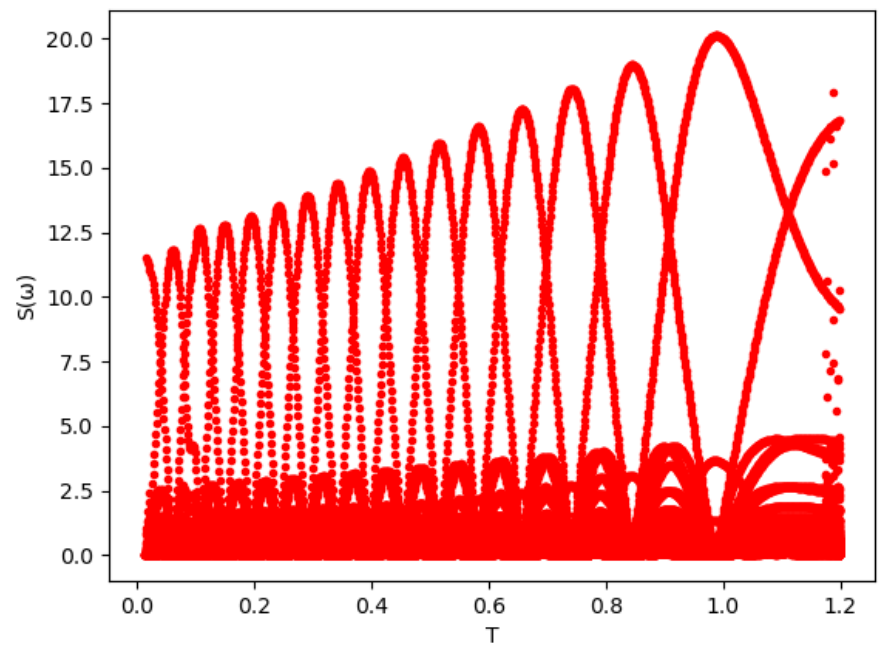

b) $K=0.001$ the present authors, this process is accompanied by the disappearance of the multimode structure, and the appearance of a wave of the incommensurate modulation with a small number of harmonics. This clearly demonstrates the appearance of a chaotic state with increasing parameter $K$, which describes the anisotropic interaction.

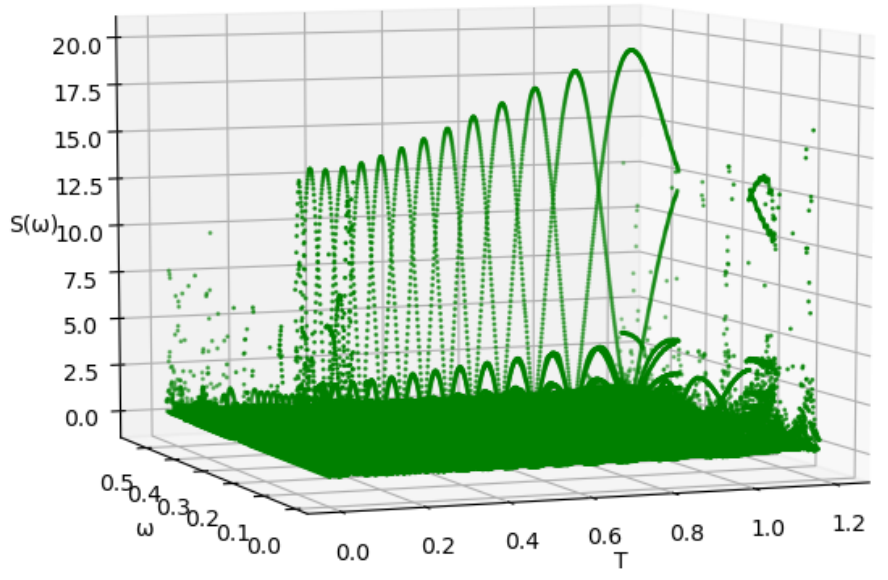

a) $K=0.3$

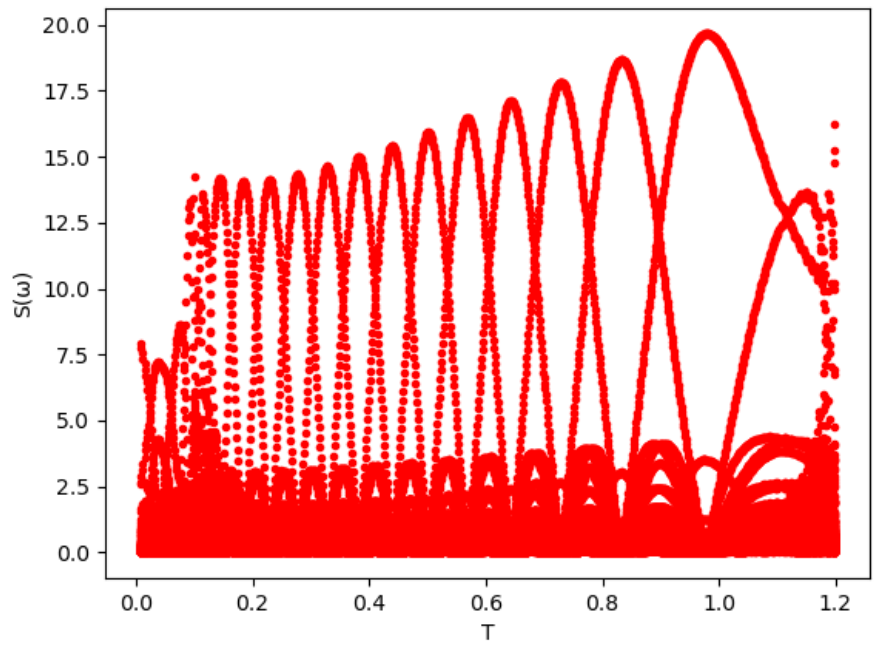

b) $K=0.1$

Fig. 5. The Fourier spectrum of oscillations of the amplitude function of the superstructure from the value of the long-range interaction (which is described by parameter $T$ ) for $n=4$, at constant values of the anisotropic interaction $K$

The emerging IC superstructure at $T_{i}$ is characterized by a set of amplitude oscillation frequencies for small values of $K$ and $T$.

Comparing the obtained spectra for $n=3$ and $n=$ 4 , it should be noted that the spectrum of existing oscillation frequencies for $n=3$ is "richer" and shows a more complex dynamics in the transition from one mode to another.

The process of increasing the magnitude of the anisotropic interaction is accompanied by a redistribution of energy between the existing frequencies in favor of oscillations with a smaller period, which leads to the transition of the modulation IC to the soliton mode. Considering the dependence of $S(\omega)$ on $K$ for $n=4$, it should be noted that in the vicinity of $K \sim 2.0$, there is a redistribution of energy, up to a change in the oscillation frequency of the zero harmonic (Fig. 6). This change in the oscillation spectrum of IC modulation is accompanied by a change in the slope of the dependence $q \sim f$ $(K)$.

The transition to the soliton regime is accompanied by the appearance of new oscillations $(K=2.1$ for $n=4$ and $K=0.6$ for $n=3)$. Subsequent changes in parameter $K$ cause the appearance of chaotic behavior $q$, which indicates the transition of the system to the stochastic mode of the superstructure with the emergence of a chaotic phase $(K>4.2$ for $n=4$ and $K \geq 1.5$ for $n=3)$. 


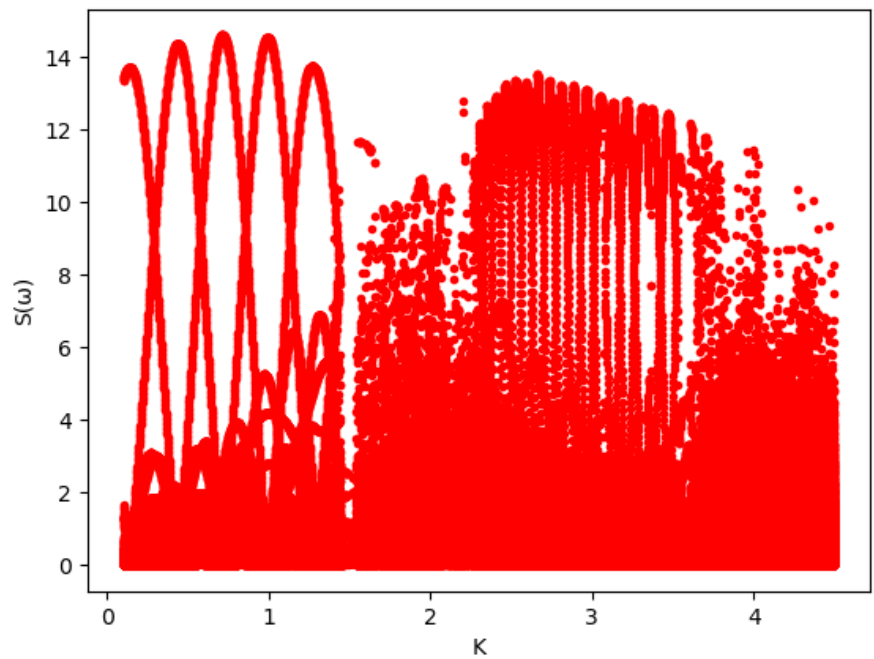

a)

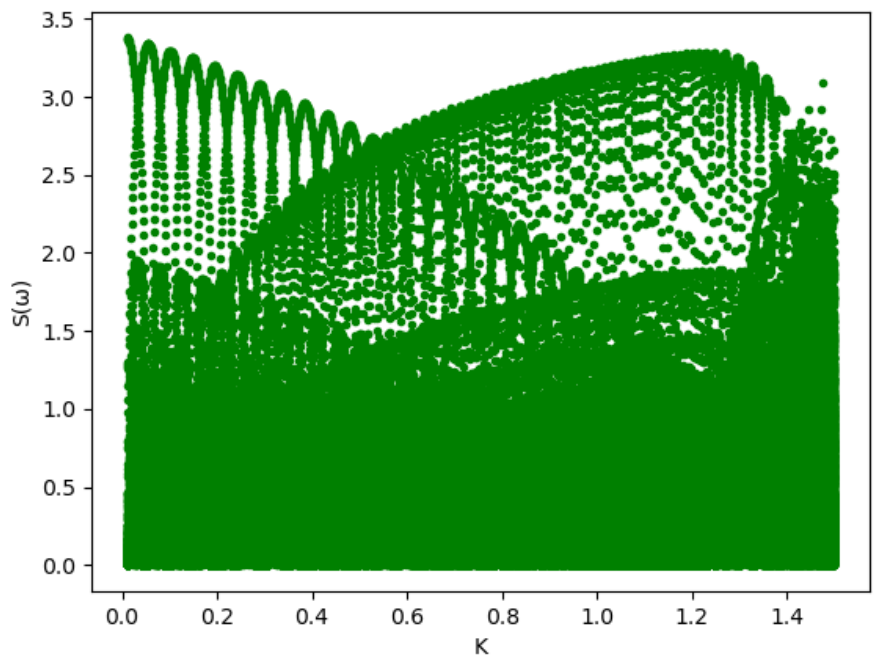

b)

Fig. 6. The Fourier spectrum of oscillations of the amplitude function of the superstructure from the value of the anisotropic interaction (which is described by parameter $K$ ) for: a) $n=4$; b) $n=3$

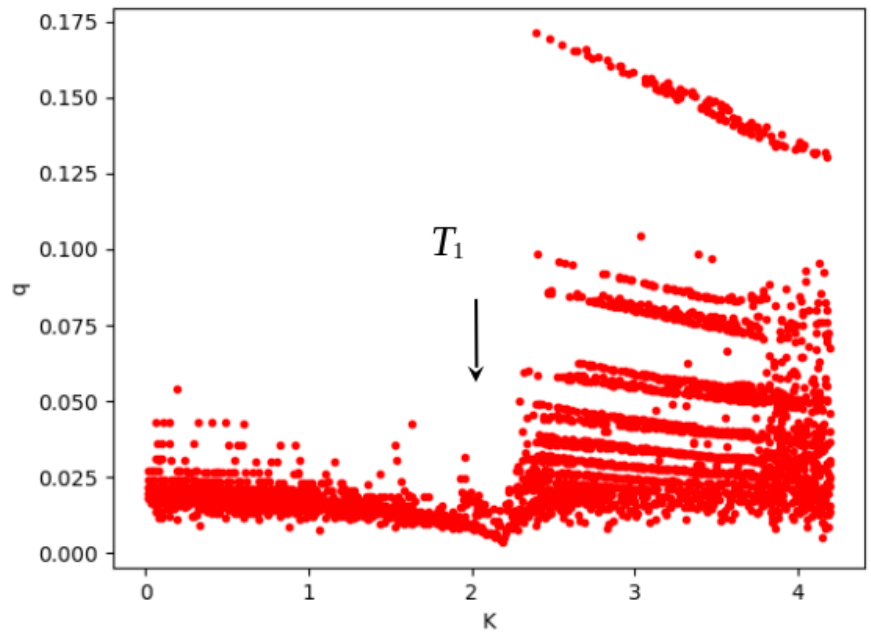

a)

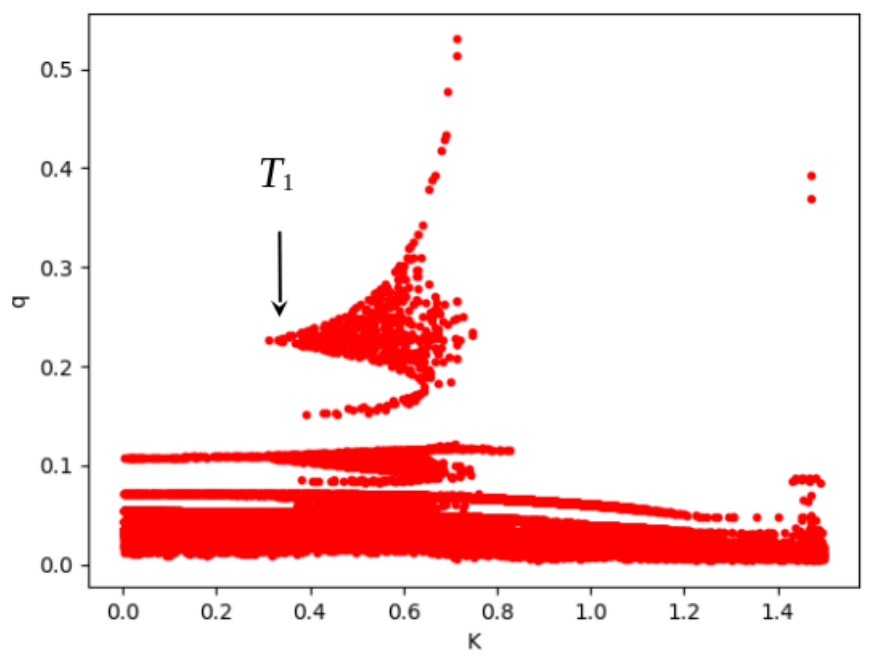

b)

Fig. 7. The dependence of the wave vector $(q)$ of the incommensurate modulation harmonics on the value of the anisotropic interaction described by the Dzialoszynski invariant (parameter $K$ ) under the condition $n=4 \mathrm{a}$ ), and $n=3 \mathrm{~b}$ )

The behavior of the harmonics of the IC modulation from parameter $K$ indicates complex transformations that occur during the transition from the sinusoidal to the soliton mode (at $T_{1}$, Fig. 7 ).

As is known [7], in the IC phase, the magnitude of the wave vector of the IC superstructure decreases with a decrease in temperature (and hence an increase in the value of the anisotropic interaction $K$ ), which indicates an increase in the modulation wavelength. In our case, there is also an increase in the wavelength of IC modulation (decrease in the value of $q$ ) (Fig. 2).

\section{CONCLUSIONS}

Based on studies of the harmonics of the IC modulation, it can be argued that the transition to the soliton mode of the IC superstructure is accompanied by a change in the frequency spectrum of the incommensurate modulation. Parameters $T$ and $K$, which are responsible for the long-range and anisotropic interactions, respectively, in the first approximation well describe the behavior of the wave vector of the IC modulation, and its modes. The origin of IC modulation is accompanied by the 
appearance of an unstable chaotic state in the case of a nonzero value of the anisotropic interaction. An increase in the value of the anisotropic interaction in the IC phase is accompanied by a change in both the frequency of existing oscillations and the magnitude of their contribution to the formation of a wave of the incommensurate modulation, causing a change in the IC modulation regime. As for the dynamics of the IC modulation wave when changing parameters $T$ and $K$, the presence of modulation IC modes is a regular process. The transition from one mode to another is continuous, and the modes themselves are determined by the dominant contribution of the respective oscillation frequencies. Thus, when a modulation wave emerges, a whole spectrum of possible frequencies arises, and with an increase in the anisotropic interaction, the process of emergence of new harmonics and redistribution of their contribution takes place.
[1] I. Kunyo, I. Karpa, S. Sveleba, I. Katerynchuk, Dimensional Effects in Dielectric Crystals $\left[\mathrm{N}\left(\mathrm{CH}_{3}\right)_{4}\right]_{2} \mathrm{MeCl}_{4}(\mathrm{Me}$ $=C u, Z n, M n, C o$ ) with an Incommensurate Phase (Ivan Franko National University of Lviv, 2019).

[2] S. Sveleba et al., Electonics Inf. Technol. 13, 108 (2020); https://doi.org/10.30970/eli.13.11.

[3] Yu. A. Izyumov, M. T. Syromyatnikov, Phase Transitions and Symmetry of Crystals (Nauka, Moskva, 1984).

[4] A. Gerrit, Chaos 28, 043116 (2018); https://doi.org/ $10.1063 / 1.5019320$

[5] S. Sveleba, I. Katerynchuk, I. Kunyo, I. Karpa, Ya. Shmygelsky, Electonics Inf. Technol. 13, 96 (2020); https://doi.org/10.30970/eli.13.10.
[6] U. Feudel, C. Grebogi, Phys. Rev. Lett. 91, 134102 (2003); https://doi.org/10.1103/PhysRevLett.91.1 34102.

[7] H. Z. Cummins, Phys. Rep. 185, 211 (1990); https:// doi.org/10.1016/0370-1573(90) 90058-A.

[8] S. Sveleba, I. Katerynchuk, O. Semotyuk, O. Fitsych, Visn. Lviv Univ. Ser. Phys. 34, 30 (2001).

[9] D. G. Sannikov, V. A. Golovko, Izv. USSR Acad. Sci. Ser. Phys. 53, 1251 (1989).

[10] S. Sveleba et al., Visn. Lviv Univ. Ser. Phys. 39, 76 (2006).

[11] S. A. Sveleba et al., Ukr. J. Phys, 53, 1098 (2008).

\title{
ФУР'Є-СПЕКТР КОЛИВАНЬ АМПЛІТУДНОЇ ФУНКЦІї НЕСУМІРНОЇ НАДСТРУКТУРИ ВІД ВЕЛИЧИНИ АНІЗОТРОПНОЇ ВЗАЕМОДІї, ЩО ОПИСУЄТЬСЯ ІНВАРІАНТОМ дзялошиНСЬКОГо
}

\author{
С. Свелеба ${ }^{1}$, I. Катеринчук ${ }^{1}$, I. Куньо ${ }^{1}$, I. Карпа ${ }^{1}$, O. Семотюк $^{2}$ \\ 1 Лъвівсъкий націоналъний університет імені Івана Франка, вул. Тарнавсъкого, 107, Лъвів, Украӥна \\ 2 Украӥнсъка академіл друкарства, вул. Під Голоском, 19, Лъвів, Украӥна
}

У роботі досліджено фур'є-спектр несумірної модуляції та залежності хвильового вектора $(q)$ несумірної (HC) надструктури від величини анізотропної взаємодії, що описується інваріантом Дзялошинського $(K)$, та далекодійної взаємодії $(T)$. Проаналізовано фур'є-спектр у різних режимах НС модуляції.

Розраховано просторові зміни амплітуди та фази параметра порядку чисельним методом BDF i виконано в середовищі Python із використанням бібліотек SciPy, JiTCODE за методикою, описаною в роботі.

Параметри $T$ і $K$, які відповідають за далекодійну та анізотропну взаємодію, відповідно, у першому наближенні добре описують поведінку хвильового вектора НС модуляції та її режими. За умови відмінного від нуля значення анізотропної взаємодії зародження НС модуляції супроводжується появою нестійкого хаотичного стану. Збільшення величини анізотропної взаємодії в НС фазі відбуваєтьсся зі зміною як частоти наявних коливань, так і величини їхнього внеску у формуванні хвилі несумірної модуляції, зумовлюючи зміну режиму НС модуляції. Перехід від одного режиму до іншого $є$ неперервним, а самі режими визначаються домінантним внеском відповідних частот коливань. Під час зародження НС хвилі модуляції виникає весь спектр можливих частот, а зі збільшенням анізотропної взаємодії - їхніх гармонік та перерозподіл їхнього внеску.

Ключові слова: несумірна модуляція, надструктура, спектр Фур'є, хвильовий вектор. 